\title{
Long survival of a patient with Marshall-Smith syndrome without respiratory complications
}

\author{
D Sperli, D Concolino, C Barbato, P Strisciuglio, G Andria
}

\begin{abstract}
The Marshall-Smith syndrome is characterised by overgrowth, accelerated skeletal maturation, and dysmorphic facial features, often associated with mental retardation of variable degree. Most of the reported patients died in the first three years of life mainly because of respiratory problems. We describe a 5 year old patient with this rare syndrome, who has optic atrophy and agenesis of the corpus callosum, but has no respiratory problems so far. This observation underlines the clinical variability of the MarshallSmith syndrome and indicates that life expectancy may be prolonged. (f Med Genet 1993;30:877-9)
\end{abstract}

The Marshall-Smith syndrome (MSS) is characterised by overgrowth, accelerated skeletal maturation, and facial dysmorphism, often associated with mental retardation of variable degree. ${ }^{12}$ The dysmorphic facial features include frontal bossing, prominent eyes, blue sclerae, small nose with anteverted nares, long philtrum, and micrognathia. ${ }^{1-3}$ Occasionally, other anomalies have been reported, such as choanal atresia, ${ }^{4-6}$ abnormal larynx or laryngomalacia, ${ }^{278}$ umbilical hernia or omphalocele, ${ }^{167}$ cardiovascular defects, ${ }^{5}$ hydronephrosis, and

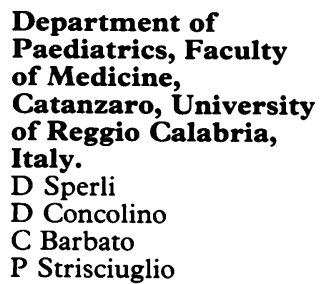

Department of Pediatrics, University of Naples, Naples, Italy.

G Andria

Correspondence to Dr Strisciuglio, Department of Paediatrics, Ospedale 'A Pugliese', Viale Pio X, 88100 Catanzaro, Italy.

Received 14 September 1992. Revised version accepted 7 April 1993.

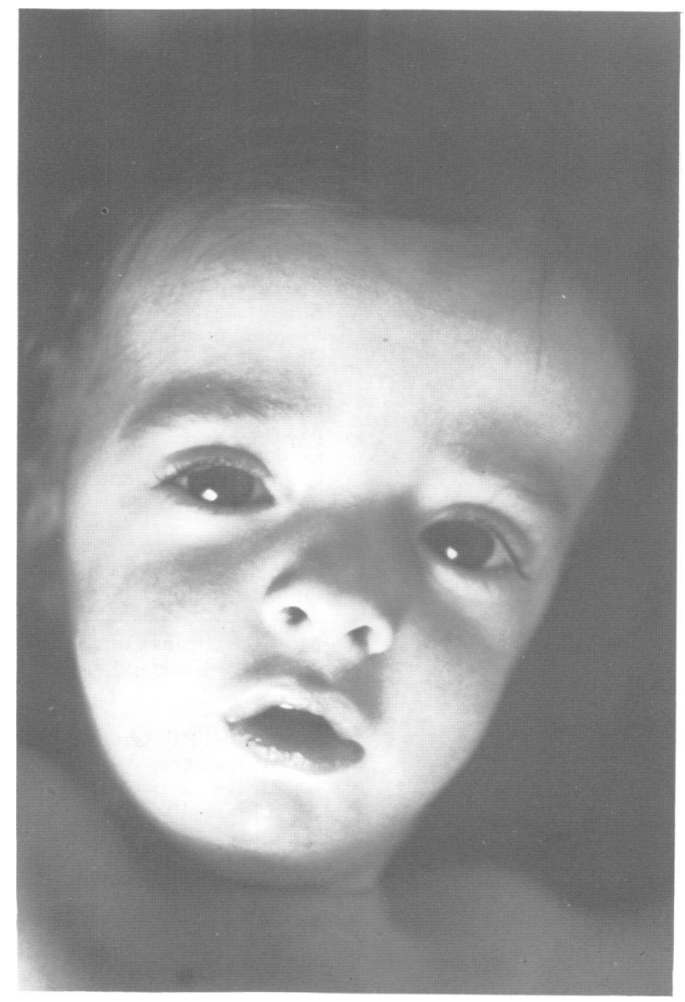

Figure 1 The patient's face at 4 weeks of age. immunological abnormalities. ${ }^{7}$ The clinical course in MSS patients is characterised by failure to thrive and severe respiratory problems, ${ }^{278}$ which are the main cause of death in the first three years of life.

We report an additional case of this rare syndrome, who has no respiratory problems so far and is still alive at 5 years of age.

\section{Case report}

The proband, a male, is the third child of healthy, unrelated parents. A previous pregnancy ended in spontaneous abortion during the first trimester. The family history is unremarkable.

The child was born at term after an uncomplicated pregnancy with a birth weight of $3780 \mathrm{~g}$ ( $>90$ th centile), length of $54 \mathrm{~cm}$ ( $>90$ th centile), and head circumference of $38 \mathrm{~cm}$ ( $>90$ th centile). His neonatal course was characterised by difficulty in sucking and failure to thrive. Clinical examination at 4 weeks of age showed mild trigonocephaly with frontal bossing, a peculiar facial appearance, long extremities, and hypotonia. The facial features included downward slanting palpebral fissures, shallow orbits, blue sclerae, megalocornea (12 mm, >95th centile), flat nasal bridge, anteverted nares, long philtrum, severe micrognathia, and low set ears with underdeveloped helix and anthelix (fig 1). In addition,

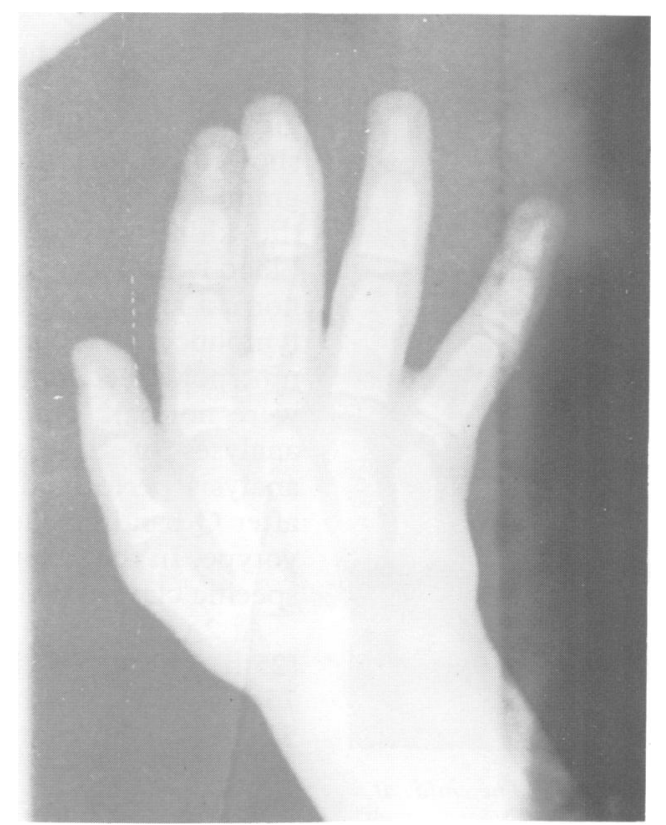

Figure 2 Widening of the third and fourth metacarpals, broad proximal and middle phalanges, and narrow distal phalanges. Advanced skeletal maturation corresponding to 3 years was also present. 


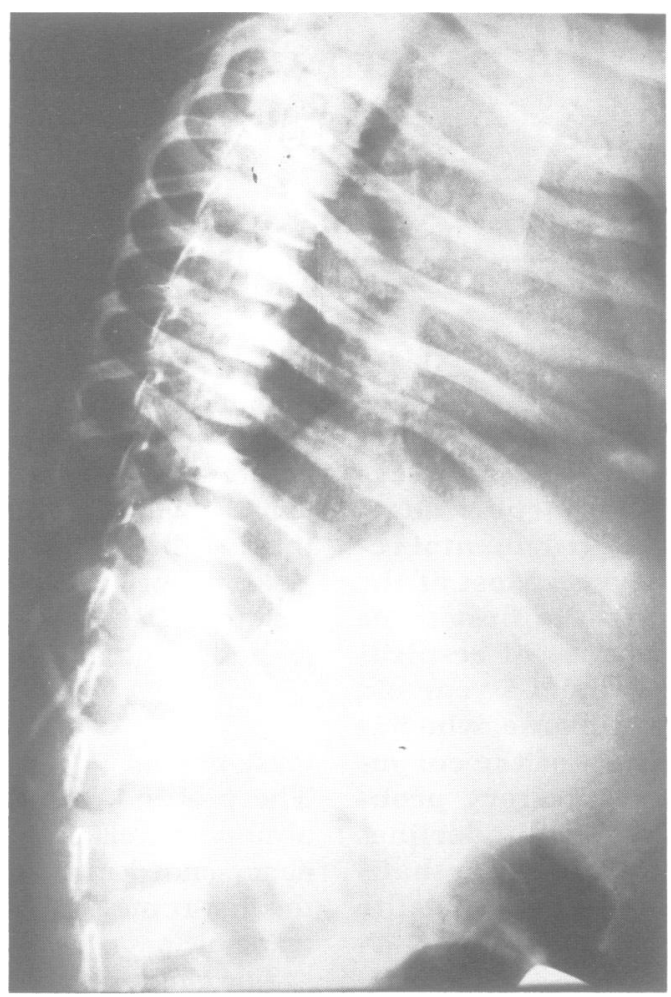

Figure 3 Thin, long ribs and dysmorphic profile of the lumbar vertebral bodies are present.

the infant had large hands with long fingers, abnormal palmar creases, long feet, and hypertrichosis. A skeletal survey showed markedly advanced skeletal maturation corresponding to the age of 3 years and increased bone density. The hands (fig 2) showed widening of the third and fourth metacarpals, broad proximal and middle phalanges, and narrow distal phalanges. Other anomalies included thin long bones, especially the ribs (fig 3 ), humeri, radii, and ulnae, a dysmorphic profile of the lumbar vertebral bodies (fig 3 ), and bending of the femora.

CT scan of the head showed partial posterior agenesis of the corpus callosum. Ophthalmological study with examination of the fundus showed bilateral optic atrophy. Electrocardiogram, echocardiogram, and sonogram of the kidneys were normal. Total peripheral blood lymphocyte count and morphology were normal and serum immunoglobulins, in vitro lymphocyte responses to phytohaemagglutinin, pokeweed mitogen, and concanavalin $A$ were normal. The results of routine urinary analyses were also normal. Chromosome analysis performed on peripheral blood cells after $\mathrm{Q}$ banding showed a normal 46,XY karyotype. In the following years the child had no specific clinical problems.

At 2 years 5 months his weight was $12.95 \mathrm{~kg}$ (25th centile), his height was $94 \mathrm{~cm}$ (50th to 75 th centile), and his head circumference was $51 \mathrm{~cm}$ ( $>95$ th centile). Severe mental retardation was present, as assessed by the Brunet test $(\mathrm{IQ}=0 \cdot 35$, normal $>0 \cdot 80)$.

At present, at the age of 5 years (fig 4), further physical examination showed a weight of $12.9 \mathrm{~kg}$ ( <5th centile), a height of $104 \mathrm{~cm}$ (10th to 25 th centile), and a head circumfer- ence of $52 \mathrm{~cm}$ (within $2 \mathrm{SD}$ ). The child is failing to thrive, but has no respiratory problems. He continues to display significant developmental retardation and absence of speech. Neurological evaluation showed a stumbling gait with a wide base and poor muscle strength. The cranial nerves are normal. Another $x$ ray of the hands showed a bone age of 10 years.

\section{Discussion}

Our patient has the typical features (table) of the MSS, including characteristic facies, accelerated skeletal maturation, abnormalities of the phalanges on $x$ ray, and motor and mental retardation. ${ }^{128}$ There was also hypertrichosis, blue sclerae, and small facial bones, as frequently described in previously published cases. ${ }^{28}$ Intestinal villous atrophy, myopathy, and partial growth hormone deficiency reported in some patients with $\mathrm{MSS}^{9}$ have not been investigated in our case because he did not show clinical signs suggesting these conditions. The agenesis of the corpus callosum and optic atrophy seen in our patient have not been previously reported.

Despite all the cases with MSS described so far $^{2}$ having respiratory problems frequently leading to early death, these are not present in our patient to date. The presence of optic atrophy and agenesis of the corpus callosum and the absence of respiratory problems underlines the clinical variability of the Marshall-Smith syndrome and indicates that the morbidity can be less severe than suggested by the clinical course of the other reported patients.

Features of the Marshall-Smith syndrome.

\begin{tabular}{lcc}
\hline Clinical findings & $\begin{array}{c}\text { Previous } \\
\text { reports }\end{array}$ & $\begin{array}{c}\text { This } \\
\text { patient }\end{array}$ \\
\hline Accelerated osseous maturation & $19 / 19$ & + \\
Broad phalanges & $18 / 18$ & + \\
Failure to thrive & $11 / 14$ & + \\
Neurodevelopmental abnormalities & $14 / 14$ & + \\
Structural brain anomalies & $7 / 15$ & + \\
Respiratory tract abnormalities & $15 / 19$ & - \\
Recurrent pneumonia & $14 / 19$ & - \\
Pulmonary hypertension & $4 / 19$ & - \\
Death in early infancy & $10 / 19$ & - \\
Prominent forehead & $16 / 19$ & + \\
Small face & $13 / 19$ & + \\
Prominent eyes & $17 / 19$ & - \\
Blue sclerae & $11 / 19$ & + \\
Flat nasal bridge & $18 / 19$ & + \\
Anteverted nares & $15 / 16$ & + \\
Micrognathia & $15 / 19$ & + \\
Glossoptosis & $6 / 18$ & - \\
Choanal atresia/stenosis & $3 / 18$ & - \\
Hypertrichosis & $8 / 19$ & + \\
Umbilical hernia & $6 / 18$ & - \\
Agenesis of corpus callosum & $0 / 19$ & + \\
Optic atrophy & $0 / 19$ & + \\
\hline
\end{tabular}

Modified from Cohen MM, Jr. Marshall-Smith syndrome. Adv Hum Genet 1989;18:254-62.

1 Marshall RE, Graham CB, Scott CR, Smith DW. Syndrome of accelerated skeletal maturation and relative failure to thrive: a newly recognized clinical growth disorder. $\mathcal{f}$ Pediatr 1971;78:95-101

2 Cohen MM Jr. Marshall-Smith syndrome. Adv Hum Genet 1989;78:95-101.

3 Charon A, Gillerot Y, Van Maldergem L, Van Schaftingen MH, de Bont B, Koulischer L. The Marshall-Smith syndrome. Eur $\mathcal{F}$ Pediatr 1990;150:54-5.

4 Iafusco F, D'Avanzo M, Ansanelli V. Su di un caso di accelerata maturazione scheletrica (Sindrome di Marshall). Pediatria (Napoli) 1977;85:487-96.

5 Perrin JCS, Arcinue E, Hoffman WH, Chen H, Reed JO. 
Accelerated skeletal maturation syndrome with pulmonary hypertension. Birth Defects 1976;12(5):209-17.

6 Visveshwara N, Rudolph N, Dragutsky D. Syndrome of accelerated skeletal maturation in infancy, peculiar facies and multiple congenital anomalies. $\mathcal{F}$ Pediatr 1974;84: and multiple congenital anomalies. F Pediatr 1974;84:

7 Johnson JP, Carey JC, Glassy FJ, Paglieroni T, Lipson MH.
Marshall-Smith syndrome: two case reports and a review of pulmonary manifestations. Pediatrics 1983;71:219-23. 8 Fitch N. The syndromes of Marshall and Weaver. $f$ Med Genet 1980;17:174-8.

Roodhooft AM, Van Acker J, Van Thienen MN, Martin JJ, Ceuterick C. Marshall-Smith syndrome: new aspects. Neuropediatrics 1988;19:179-82. 